\title{
El derecho a la educación inclusiva, un título en igualdad de condiciones
}

\author{
Estefanía Jacqueline Saccon
}

\section{Introducción}

La educación inclusiva en Argentina ha tenido avances pero por sobre todo cuenta con muchos desafíos. Para contar con una verdadera Educación Inclusiva para todos ${ }^{1}$, dicho concepto debe versar sobre la totalidad de la educación, es decir, tanto en su ingreso, como en la permanencia y el egreso. En ésta última etapa, una de las más ansiadas por los estudiantes, es de vital significación la obtención del título que acredite y certifique toda la trayectoria educativa, el tan ansiado título secundario.

Si bien en materia de educación inclusiva se han obtenido algunos progresos, se puede constatar actualmente hechos de la práctica cotidiana que resultan obstáculos para alcanzarla.

Desde esta perspectiva, el sistema educativo debe velar por el derecho universal a una educación inclusiva y de calidad, sin discriminación, ni segregación, valorando la diversidad, tomándola como favorecedora y enriquecedora.

Respecto esta última etapa, que consiste en la obtención del deseado título secundario, es de vital significación que el mismo acredite y certifique la trayectoria educativa. Es ese "papel" el que no sólo reflejará el gran desafío y sacrificio de cada estudiante, y que podrá conservarlo como símbolo de logro alcanzado, será el primer requisito que se pedirá para acceder a otro paso importante en su proyecto de vida: la obtención de un empleo, seguir estudiando una carrera terciaria o universitaria.

\footnotetext{
1 En este documento se procuró evitar el lenguaje sexista. Sin embargo, a fin de facilitar la lectura no se incluyen recursos como "@", "x" o "-a/as". En aquellos casos en los que no se pudo evitar el genérico masculino deseamos que se tenga en cuenta esta aclaración. La tendencia natural de las lenguas a cambiar en su desarrollo natural a través de la historia, permite potencialmente lograr una mayor inclusividad social.
} 


\section{El Derecho Universal a la Educación Inclusiva. Realidades en la titulación de la trayectoria escolar de las Personas con Discapacidad}

Históricamente se ha considerado a las personas con discapacidad como beneficiarias de ayudas sociales, pero ahora el derecho internacional las reconoce como titulares de derechos y pueden reclamar su derecho a la educación sin discriminación y sobre la base de la igualdad de oportunidades. La Convención sobre los Derechos del Niño (1989), la Declaración Mundial sobre Educación para Todos (1990), las Normas Uniformes sobre la Igualdad de Oportunidades para las Personas con Discapacidad (1993) y la Declaración de Salamanca y Plan de Acción (1994) incluyen medidas que demuestran una conciencia y una comprensión cada vez mayores del derecho de las personas con discapacidad a la educación. (Comité sobre los Derechos de las Personas con Discapacidad. Observación general núm. 4, 2016)

La Convención sobre los Derechos de las Personas con Discapacidad de las Naciones Unidas (en adelante, CDPCD), con jerarquía constitucional (Art. 75 inc. 22) en su artículo 24 primer párrafo dispone "Los Estados Partes reconocen el derecho de las personas con discapacidad a la educación. Con miras a bacer efectivo este derecho sin discriminación y sobre la base de la igualdad de oportunidades, los Estados Partes asegurarán un sistema de educación inclusivo a todos los niveles así como la enseñanza a lo largo de la vida (...)".

Es menester resaltar que la norma dispone "sin discriminación", es decir, que a toda persona (con o sin discapacidad) que ingresa a la escuela y cumple toda su trayectoria allí, cuando se gradúa obtendría su título, en igualdad de condiciones. Dicho título permite, cumplir con la formalidad requerida poder seguir estudiando u obtener un empleo.

Para cumplir tal misión, los alumnos deberían encontrarse en un sistema inclusivo, un sistema que les permita ingresar y/o permanecer en igualdad de oportunidades respecto de todos. 
Actualmente en nuestro sistema educativo coexisten dos tipos o modalidades de institución educativa, una denominada "escuela común" y otra denominada "escuela especial". Originariamente en las escuelas comunes asistían todos los niños, menos los que poseían alguna deficiencia, ya que éstos eran inscriptos en centros educativos diseñados específicamente para responder a una deficiencia concreta, normalmente en un sistema de enseñanza especial. Esta forma de educación es una educación basada en la "segregación", ya que se basa en el modelo médico/rehabilitador el cual considera que la persona con discapacidad es un objeto de la medicina, con un problema de salud, que debe rehabilitarse para ser considerada parte de la sociedad.

Es así que el diagnóstico médico de la persona será el que decida a que escuela debe ir, y qué educación debe recibir. Es un sistema que segrega y discrimina, ya que las personas van a escuelas distintas y reciben distintos tipos de educación.

Luego de estas dos instituciones educativas, con el avance del modelo social ${ }^{2}$ de la discapacidad se comenzó a adoptar otro sistema de educación, pero manteniendo las dos instituciones, tanto la escuela común como la escuela especial, que es lo que llamamos "integración", que se basa en tratar de normalizar a la persona, intentar que la misma pueda ser igual a un patrón estándar.

En este caso se permite que ciertos alumnos con discapacidad ingresen a una escuela común, siempre y cuando respondan al sistema educativo, tal como el mismo esta propuesto, y van a poder permanecer en la escuela común siempre y cuando respondan a lo que se les exige, sino tendrán que concurrir a la denominada educación especial.

\footnotetext{
2 El modelo social de la discapacidad es adoptado por la Convención sobre los Derechos de las Personas con Discapacidad, y es el que sostiene que la discapacidad no es un problema de la persona, sino el resultado del encuentro entre las características de la persona y la forma en que fue diseñada la sociedad. Es decir, la discapacidad está en las barreras que la sociedad les interpone a las personas con discapacidad, que impiden la plena inclusión y participación en todos los ámbitos de la vida.
} 
Tanto el sistema educativo de segregación, el cual toda persona o niño con discapacidad debía ser educado en una escuela especial, como un sistema educativo de integración, el cual permite el ingreso y permanencia de la persona con discapacidad en la escuela común siempre y cuando se adecue y responda a las exigencias de la misma, responden a modelos medico/rehabilitador, que segregan, excluyen, y discriminan a todas las personas con discapacidad, y en nada se asemejan a la educación inclusiva, la cual refleja la realidad de nuestra sociedad, que todas las personas somos diferentes, todos los niños y niñas son diferentes, y que la escuela no debe esperar que todos hagan lo mismo de la misma manera sino que, partiendo de que todos somos diferentes se cambia la lógica.

Tampoco se espera menos de ningún alumno, sino se tiene que esperar lo máximo de cada estudiante y se debe dar a cada uno todos los apoyos y medios para que logren su trayectoria escolar. Es la escuela la que debe transformarse para educar a todos sus alumnos, sin importar sus características.

En la actualidad, lo que ocurre mayormente son dos cuestiones: en primer lugar, muchos niños con un diagnostico medico (que decide sobre toda su vida, como un estigma) son inscriptos directamente en una escuela especial y, en segundo lugar, los que quieren ser inscriptos en una escuela modalidad común, como el resto de todos los niños, reciben una serie de obstáculos, con frecuencia negativas ${ }^{3}$ a la matriculación. Solo unos pocos logran ingresar a escuelas comunes ${ }^{4}$. Cada vez que el padre, madre o responsable del niño o niña se acerca a una escuela para inscribir a su hijo, es una gran batalla llena de dolor, sufrimiento, prejuicios, y discriminación. Los pocos que pueden ingresar a una escuela común, al momento de su egreso, continúan con los problemas cuando tienen que recibir

3 Estas conductas configuran actos de discriminación por motivos de discapacidad, prohibidos por normas nacionales e Internacionales.

4 Recordemos que el derecho a la educación no es solo el que haya escuelas, es que todo niño o niña pueda acceder a ella, pueda ingresar, permanecer y egresar de la misma. 
su título para poder ingresar al mercado laboral o continuar con sus estudios.

En esta etapa que denominamos titulación, nos surge el siguiente interrogante ¿qué ocurre en la práctica cotidiana en el sistema de titulación? Acercándonos a una respuesta constatamos que hoy en día una persona con discapacidad que transita todo su recorrido en la escuela "común", con sus apoyos y adaptaciones necesarios, cuando se gradúa no obtiene el mismo título que el resto de sus compañeros (situación que denota una falacia al concepto de "sin discriminación").

Pese a las conquistas de nuestro país en materia de derechos humanos y educación inclusiva, y aún en el actual modelo social de las personas con discapacidad, todavía subsiste como un sistema escolar segregado la denominada "Escuela Especial". Aunado a ello, la brecha entre el deber ser y la realidad se acrecienta, toda vez que alcanzada la meta máxima en la escolaridad, se le otorga a la persona con discapacidad un título "no homologable", que opera como un obstáculo al real acceso a un empleo o a niveles superiores de educación.

Esta opción de escolarización para las personas con discapacidad no se ha extinguido en la actualidad y, con el correr del tiempo, se ha ido cuestionando pero aún subsiste firmemente. Incluso han modificado su "fachada", adosándole formalmente el criterio de integración, pero su objetivo sigue siendo el mismo.

La Inclusión muchas veces es tomada como un sinónimo de integración. Pero no lo es. La integración educativa contempla que una persona con discapacidad pueda ingresar a una escuela "común" y que la dejen permanecer en ella. En cambio, la inclusión va mucho más allá. No es sólo el ingreso, sino que

5 La educación especial fue creada con la idea de que había niños normales y niños diferentes. A estos niños "diferentes" les convendrían ámbitos y destinos institucionales diferentes. La educación especial tomó una orientación basada en el modelo médico, en el cual se pone el énfasis en el déficit y se favorece la segregación. Este principio marcó la creación de la escuela especial y continúa con algunos resabios en la actualidad. 
el sistema educativo le asegure el apoyo y adaptaciones necesarias para el acompañamiento de sus trayectorias escolares en igualdad de condiciones y sin discriminación.

Cuando hablamos de inclusión en educación, hablamos de una "Educación para todos", no solo para las personas con discapacidad como usualmente se supone, sino una educación sin segregación o discriminación por etnia, género, nacionalidad, procedencia social, capacidades o características personales. Una educación de calidad sin ningún tipo de discriminación ya sea dentro o fuera del sistema escolar, lo cual exige una transformación profunda de los sistemas educativos.

Un Sistema Educativo Inclusivo, propicia una sociedad inclusiva, pacífica y justa, una sociedad en donde todos pueden participar, tener voz, decisión, y donde la diversidad es valorada y apreciada.

La verdadera inclusión va más allá del acceso, implica el máximo aprendizaje y desarrollo de las potencialidades de cada persona. La inclusión así entendida supone un paso hacia delante respecto del movimiento de la integración. Este último se contenta con asegurar el derecho de las personas con discapacidad a educarse en las escuelas comunes, mientras que la inclusión aspira a hacer efectivo para toda la población el derecho a una educación de calidad, preocupándose especialmente de aquellos que, por diferentes causas, están excluidos o en riesgo de ser marginados. Los elementos que definen el derecho a la educación entendido en su sentido más amplio son una educación de calidad que posibilite el aprendizaje desde el nacimiento y a lo largo de la vida; obligatoriedad y gratuidad, universalidad y no discriminación; participación, y derecho a un trato justo y a una educación que incluya a todos. (Blanco Guijarro R., 2008)

Como figura en el informe de la Oficina del Alto Comisionado de las Naciones Unidas para los Derechos Humanos acerca del estudio temático sobre el derecho de las personas con discapacidad a la educación, solo la educación inclusiva 
puede ofrecer educación de calidad y desarrollo social a las personas con discapacidad, y una garantía de universalidad y no discriminación en el derecho a la educación. (Comité sobre los Derechos de las Personas con Discapacidad. Observación general núm. 4, 2016)

\section{Ajustes y resistencias legislativas}

El cambio de paradigma que trae aparejado la Convención de los Derechos de las Personas con Discapacidad debería devenir un cambio profundo en materia de legislación de nuestro país. Aún luego de 9 años de la ratificación y aprobación de la Convención sobre los Derechos de las Personas con Discapacidad y su protocolo facultativo por Argentina, restan muchos desafíos y obligaciones en materia legislativa, como también de políticas públicas.

Recordemos que la CDPCD en su artículo 4 establece las obligaciones generales por parte de los Estados, el cual dispone en sentido general adoptar todas las medidas legislativas, administrativas y de otra índole que sean pertinentes para hacer efectivos los derechos reconocidos en la presente Convención. También dispone que los Estados se comprometen a tomar todas las medidas pertinentes, incluidas medidas legislativas, para modificar o derogar leyes, reglamentos, costumbres y prácticas existentes que constituyan discriminación contra las personas con discapacidad, como a su vez abstenerse de actos o prácticas que sean incompatibles con la Convención y velar por que las autoridades e instituciones públicas actúen conforme a lo dispuesto en ella.

En la actualidad la Educación Inclusiva en la Provincia de Buenos Aires, se rige por la Resolución No 1664/17 de la Dirección General de Cultura y Educación (en adelante, DGCyE), que deroga la aciaga Resolución 4635/11 de la DGCyE. Esta última resolución establecía los lineamientos para la "integración" de los "sujetos con discapacidad", y a su vez resaltaba la palabra "limitaciones" y "capacidades", textualmente en el cuerpo de la 
resolución esbozaba: "permitir que el alumno descubra sus propias capacidades reconociendo sus limitaciones", palabras que en este contexto denotan terminología y pensamientos basados en el anterior modelo y no en el modelo o paradigma actual (paradigma social).

En cuanto a la certificación, establecía en su Anexo II que "La calificación, acreditación y certificación la realizará la Dirección que corresponda de acuerdo con las situaciones particulares de cada alumno y a lo pautado en el Acuerdo Pedagógico y en el Proyecto Pedagógico Individual”.

Respecto al tema central del presente trabajo, la homologación del título de nivel secundario, dicha Resolución expresaba que "los alumnos que con su Proyecto Pedagógico Individual cumplimenten los Contenidos del Diseño Curricular de Nivel Primario, recibirán el certificado de finalización expedido conjuntamente por el Nivel y la Modalidad y firmado por el Director e Inspector de ambas escuelas", es decir, que aunque el alumno sea "integrado" en una escuela "común", no recibiría el mismo título que sus compañeros sin discapacidad.

Como adelanté, dicha resolución no nos habla de "Inclusión", sino de "integración" que como aludimos precedentemente, no son sinónimos, ni tampoco corresponde a lo establecido por la convención.

Además, dicha normativa siempre estaba centrada en el alumno, si el mismo no lograba los objetivos propuestos solo sería consecuencia de su discapacidad o de sus características.

Con la nueva resolución $\mathrm{N}^{\circ}$ 1664/17 de la DGCyE denominada "Educación Inclusiva de Niñas, Niños, Adolescentes, Jóvenes y Jóvenes-Adultos con Discapacidad en la Provincia De Buenos Aires", comenzamos a tratar de adecuar nuestra legislación interna a la Convención sobre los derechos de las Personas con Discapacidad ${ }^{6}$. La misma entre sus fundamentos

6 La Convención sobre los Derechos de las Personas con Discapacidad, en su Art. 4 establece, entre otras cuestiones, que los Estados Partes, como lo es Argentina, se comprometen a "Adoptar todas las medidas legislativas, administrativas y de otra índole que 
establece "la educación inclusiva es un derecho de todas las personas que se despliega en la actualidad como un borizonte pedagógico que no queda reducida ni limitada únicamente a la educación de los estudiantes con discapacidad, sino que da cuenta del reconocimiento de las particularidades y necesidades de cada uno y de todos los alumnos", aquí vemos que esta nueva resolución a tenido un notable avance en cuanto a ser sustentada en una educación sin discriminación, universal, inclusiva y de calidad.

En cuanto a los principios que establece esta nueva resolución, uno de ellos es que la sola presencia de un niño, niña, adolescente, joven o joven-adulto con discapacidad por sí sola no torna necesaria la intervención de la modalidad especial. Este principio, dentro del escenario del cual venimos, considero que es un pequeño progreso, ya que destaca que no porque haya un alumno con discapacidad debe intervenir la modalidad especial. Igualmente, desde ya les anticipo, que no es lo que sucede en la realidad. Asimismo, se considerará la articulación con la modalidad de educación especial solo cuando la niña, el niño o adolescente con discapacidad lo requiera, en acuerdo con su familia y la institución educativa del nivel y/o modalidad.

En cuanto al tema que nos ocupa, en primer lugar con respecto a la certificación en el nivel secundario, menciona que será responsabilidad de la institución del nivel secundario en la que se encuentran inscriptos los estudiantes con discapacidad. El titulo o certificado analítico, tema central de este trabajo, será otorgado por la institución educativa del nivel en la que los/las estudiantes con discapacidad hayan cursado su ultimo año. Es decir, según dicha normativa si cursó en una escuela común hasta su ultimo año debería obtener el titulo conjuntamente con el de sus compañeros. Continua también expresando que la

sean pertinentes para hacer efectivos los derechos reconocidos en la presente Convención y a tomar todas las medidas pertinentes, incluidas medidas legislativas, para modificar 0 derogar leyes, reglamentos, costumbres y prácticas existentes que constituyan discriminación contra las personas con discapacidad". 
Propuesta Pedagógica Inclusiva ${ }^{7}$ (en adelante PPI) habilitará a los estudiantes con discapacidad a recibir el titulo o certificado analítico del Nivel, al igual que el resto de la población escolar, dando cuenta de su trayectoria educativa.

Aunque parece ser muy claro, en la práctica suceden muchas resistencias, incluso situaciones que la resolución no plantea como el caso de los alumnos que terminaron su secundario antes de dicha resolución y obtuvieron un título no homologable ¿Qué sucede aquí?, ¿podría cada uno reclamar su titulo homologable? ¿Qué sucede si finalizó sus estudios secundarios antes de dicha resolución, pero en el presente desea continuar sus estudios? ¿le será negado su derecho? En la práctica suceden numerosas situaciones de desigualdad y desconocimientos de derechos fundamentales como lo es el derecho a la educación. Esta resolución solo hace mención en una nota al pie sobre dicha particularidad, dando una solución un tanto ambigua ya que establece que "para aquellas personas con discapacidad que hayan finalizado sus estudios en años anteriores a la firma de la presente norma, el Nivel secundario con las modalidades correspondientes, llevarán a cabo un análisis de cada trayectoria educativa a los fines de su evaluación y consideración”.

Una situación tan importante, como lo es el titulo secundario para miles de alumnos que egresaron antes de la presente resolución solo se menciona en una nota al pie, como si fuera algo superfluo e irrelevante dicho escenario, que solo depende

7 Consideramos el PPI como una herramienta de planificación y de sistematización de los acuerdos dinámicos entre un alumno, su familia y sus docentes en pos de garantizar las condiciones educativas que cada alumno precisa, sin olvidar nunca la calidad. En otras palabras, elaborar un PPI no es sinónimo de eximir de materias ni implica tener bajas expectativas de logro en relación a un alumno. En este sentido, la construcción de un PPI debería estar basada en la identificación de las barreras al aprendizaje y la participación del alumnado y en la construcción de acuerdos y apoyos para su eliminación. Por eso, el PPI no implica reducción de contenidos u horario, sino, por el contrario, la sistematización de las estrategias que en un período determinado la escuela implementará para efectivizar el derecho a la educación de su alumnado con discapacidad. No todos los alumnos con discapacidad requieren un PPI, aunque sí probablemente necesiten apoyos. (COPIDIS \& Grupo Artículo 24 por la Educación Inclusiva, 2017) 
del tiempo en que terminan sus estudios para poder obtener el derecho o no a su título homologable al nivel. Además, tampoco establece un procedimiento para poder analizar cada una de las trayectorias.

Es importante destacar que tanto antes de esta resolución, como ahora lo que sucede es que aun cuando las niñas y los niños alcanzan todos los logros de su proyecto pedagógico individual o propuesta pedagógica de inclusión, al momento de la acreditación, se les exige tener aprobados todos los contenidos mínimos del nivel común, y no los de la currícula adaptada. Es una contradicción y la dicción de una educación que "falsamente alude ser para todos sin discriminación".

En la mayoría de los casos los alumnos con discapacidad cuando egresan obtienen un titulo no homologable, un titulo diferente al resto de sus compañeros, un titulo que indica una resolución distinta, un sello impuesto que refuerza la idea de discriminación, o que dice "no homologable", frase asimilable a "no es válido", y bien sabemos que vivimos en un mundo donde el titulo secundario es uno de los elementos más importantes para poder acceder al mundo del trabajo, o bien seguir estudiando, derecho que será negado a toda persona que quiera ingresar al nivel terciario o secundario con un titulo no homologable.

De igual forma, resulta discordante que el sistema le permita ingresar a la escolarización, y que en el momento más importante, como lo es la entrega del título y reconocimiento de ese ingreso y trayectoria, se le entregue un papel que no le permite seguir estudiando o presentarlo como documento válido para acceder a un empleo, por el solo hecho de no reconocerlo como egresado apto.

Como también que de acuerdo a que año haya egresado tendrá un titulo homologable o un titulo no homologable, como si sus derechos dependieran exclusivamente de la suerte de haberse recibido en uno u otro año.

El título "no homologable" emitido por la Dirección General de Cultura y Educación de la Provincia de Buenos Aires al 
concluir los estudios secundarios es contrario al derecho vigente y a la jerarquía normativa que fija el art. 31 de la Constitución Nacional y el cuerpo de normas constitucionales y convencionales que aseguran el derecho a la educación a favor de personas con discapacidad, sin discriminación (art. 75, incs. 19, tercer párrafo, 22 y $23 \mathrm{CN}$.).

Luego de idas y vueltas, de resistencias y oposiciones, antes de la resolución 1664/17 contamos a nivel local con un pequeño avance con respecto a la titulación en materia de Educación Inclusiva, la Resolución 311/16 del Consejo Federal de Educación (organismo que reúne a la autoridad educativa de cada provincia argentina, donde se reúnen todos los ministros del país). Dicho consejo emitió esta Resolución por medio de la cual se ordena emitir un título secundario en igualdad de condiciones entre alumnos/as con o sin discapacidad que hayan concluido las cargas curriculares (arts. 39/40 Res. 311/16 CFE).

Expresamente dice el art. 39: "El PPI habilitará a los estudiantes con discapacidad a recibir el título y certificación analítica del nivel o modalidad, al igual que el resto de la población escolar, dando cuenta de su trayectoria educativa".

De igual manera dicha resolución en su Art. 32 establece "Todos los/as estudiantes con discapacidad que certificaron el Nivel Primario, aunque sus aprendizajes hayan guardado escasa referencia con el diseño curricular jurisdiccional del Nivel Primario, ingresarán al Nivel Secundario en cualquiera de sus modalidades con las configuraciones de apoyo, los ajustes razonables y el acompañamiento de la Educación Especial, si resultara necesario". Es decir, este derecho se reconoce incluso en el caso de Proyectos Pedagógicos Individuales que no concuerden en su totalidad con la curricula general.

De aquí se desprende que antes de la derogación de la Resolución 4635/11 de la DGCyE, por la resolución 311/16 tampoco debía ser aplicable, y no solo por ello, sino por ser contraria a la Convención Internacional de las Personas con Discapacidad (superior a toda normativa interna, sea que se 
trate de leyes, resoluciones o disposiciones de carácter nacional o local), y la Constitución Nacional, con lo cual carece de todo fundamento que la DGCyE aplique la anterior normativa o cualquier resolución que contraríe al Artículo 24 de la Convención sobre los Derechos de las Personas con Discapacidad.

En conclusión, un título no homologable, no solo es contrario a nuestra Constitución y a la Convención de los Derechos de las Personas con Discapacidad, sino al Pacto Internacional de Derechos Económicos, Sociales y Culturales, la Declaración Universal de Derechos Humanos, la Ley de Educación Nacional $\mathrm{N}^{\circ} 26206$ y la Ley de Educación Provincial $\mathrm{N}^{\circ} 13688$ y, por último, con las salvedades mencionadas precedentemente las Resoluciones 311/16 del Consejo Federal de Educación y 1664/17 de la DGCyE.

Las resoluciones del Consejo Federal de Educación son normas obligatorias de carácter federal (art. 113 de la ley 26.206 y art. 11 de la Res. 1/07 del CFE). Por resolución 2945/17 del Ministerio de Educación de la Nación se le reconoce validez nacional a los títulos emitidos conforme resolución 311/16. Es decir, no quedan dudas de que la lucha por la Educación Inclusiva desde la parte normativa ha ido avanzando, pero ahora bien ¿En la práctica esto es así? ¿O restan todavía más desafíos por lograr?

La Convención Internacional de las Personas con Discapacidad es clara con respecto a la educación inclusiva, en cuanto a la titulación sin discriminación, y en igualdad de condiciones que el resto. Pero ahora bien, ¿Qué pasa con todas las Personas con Discapacidad que se graduaron antes de la Resolución 311/16 del CFE o de la Resolución 1664/17 de la DGCyE? A ellos se les emitió un título no homologable, ¿cada uno tiene que solicitar la "reconvención de su título"? o ¿ésta resolución solo es válida para los títulos que de ahora en más van a emitirse? Por supuesto que no nos queda dudas que cuando pensamos en los derechos a un título en igualdad de condiciones, no solo hablamos del derecho "de ahora en más", sino que todas aquellas personas tienen su derecho a reclamar por su nuevo título en base al principio de no discriminación. 
Los derechos humanos y su aplicación no pueden verse vulnerados por el tiempo ni por formalismos. El derecho universal a la educación prima sobre la época en la cual se emitió un título que es violatorio de las normas convencionales y constitucionales.

Actualmente, nos queda el interrogante de cómo el sistema educativo va a llevar a la práctica este proceso de restructuración, reconversión y emisión de todos los nuevos títulos y supresión de los emitidos en contra de nuestro valioso Derecho a una Educación Inclusiva. Tal vez este proceso incluso sume y dé la posibilidad (anteriormente negada) a que muchas Personas con Discapacidad, se planteen el volver a estudiar, el seguir otra carrera, y al menos puedan tener el derecho a decidir sin que otros decidan por ellos, el gran principio de Autonomía.

Del mismo modo a desarrollar su potencial humano, eliminar esa barrera de estereotipos y prejuicios que antiguamente se les asignaba a las personas con Discapacidad. Hoy estamos un nuevo paradigma y debemos luchar por reforzarlo, promover el reconocimiento de las capacidades y las habilidades de las personas con discapacidad (Art. 8 CDPCD), derecho a vivir de forma independiente y a ser incluido en la comunidad (Art. 19 CDPCD).

\section{La Educación de las personas con discapacidad en los medios de comunicación ¿Cuál es el discurso sobre la titulación secundaria?}

La educación inclusiva es tomada en los medios de comunicación como el derecho de las personas que tienen "capacidades diferentes"8. Se sostiene como un paradigma reciente y novedoso,

8 Usualmente escuchamos diferentes términos como discapacitado, capacidades diferentes, capacidades especiales, minusválido, mogólico, inválido, impedido o deficiente, como sinónimos para definir a las Personas con Discapacidad. Es importante la forma en que nos expresamos, ya que define y difunde maneras de ver el mundo y de entender a las personas. Esto tiene consecuencias en el respeto de los derechos de esas personas, por eso es de vital importancia expresarnos correctamente y decir personas con discapacidad, porque es así como el colectivo de personas con discapacidad eligió denominarse, porque ante todo somos 
un proyecto a futuro en el cual cada padre podrá optar entre llevar su hijo a una escuela común o a una escuela de modalidad especial.

Es usual que en los discursos mediáticos subsista latente la distinción de escuelas y la diferencia entre los niños que tienen discapacidad y "el resto", como si éste fuera un grupo homogéneo que necesita de las mismas prácticas de enseñanza, de evaluación y de aprendizaje. Lo que no resulta usual es escuchar el mensaje de "una escuela para todos" y el derecho al mismo título para todos los jóvenes graduados.

Con ese norte, la educación inclusiva es tomada como problemática, en el sentido que se menciona que los docentes no están preparados. Cabe preguntarse ¿preparados para qué? ¿Acaso debemos continuar con la formación docente como hace años atrás, siendo que hoy el objetivo de la educación ha cambiado? ¿Debemos tener docentes "comunes" y "especiales"? ¿Acaso también los docentes están preparados para todas las situaciones que surgen en la escuela?

Si los grupos áulicos hoy son heterogéneos, multigrados, diferentes en cada escuela, ciudad, y con diferentes culturas ¿Por qué no podemos formar docentes para las escuelas actuales?, donde el aula es un lugar no solo de enseñanza, sino de contención, diversión, y donde "quien enseña aprende al enseñar, y que quien aprende enseña al aprender" (Freire Paulo, 2004).

Siguiendo a Camilloni (s.f.), coincidimos en que las decisiones acerca de para qué hay que aprender y, en consecuencia, qué es lo que las personas deben aprender en cada uno de los ciclos de su vida, desde la niñez hasta la edad adulta, han variado según los marcos sociales, culturales, económicos, políticos y también filosóficos, de cada pueblo, cultura, época, clase social y género. Las tradiciones parecen haber consagrar en la

\footnotetext{
personas, no nos referimos a las personas con discapacidad como "discapacitados" porque la condición no define a una persona, tampoco con los demás eufemismos como "capacidades diferentes" o los nombrados precedentemente, ya que ponen adjetivos innecesarios sobre la persona.
} 
actualidad, la necesidad de que ciertos contenidos sean aprendidos en instituciones escolares en edades determinadas, por lo que se podría pensar que los componentes fundamentales de los programas de formación en uso pueden sostenerse a lo largo del tiempo habiendo ya sufrido los inevitables procesos de decantación a los que la historia de la educación los ha sometido. No podemos seguir sosteniendo esto, como tampoco pensar que las cuestiones curriculares básicas ya han sido resueltas y que no es imprescindible someter a crítica constante los principios teóricos y prácticos que las sustentan.

Una de las operatorias que desactivan la puesta en práctica de la educación inclusiva es el afirmar en los medios de comunicación que los derechos conquistados y su puesta en práctica ya están asimilados y logrados. El tema se vio expuesto, como podrán recordar, con los casos de "Alan Rodríguez", o el de "Noelia Garella"10, casos en donde se ha puesto en boga la educación inclusiva en todos los medios de comunicación.

Durante el lapso que duraron estas noticias en los medios masivos de comunicación fue tema de discusión, de planteos, tratamiento, pero con el correr del tiempo se fue olvidando y

9 Alan Rodríguez, un chico con Síndrome de Down quien terminó el secundario en el 2013 pero el Ministerio de Educación le niega el título. Fue a una escuela común -privada de la CABA- desde los 3 años y cursó toda su primaria y secundaria con un proyecto pedagógico individual. Cumplió año a año sus objetivos, pero al finalizar, le indicaron que su título no podía ser entregado porque, según el Ministerio de Educación, no había cumplido ciertos contenidos considerados mínimos por la normativa local. Con el patrocinio jurídico de la Asociación Civil por la Igualdad y la Justicia y el apoyo del Grupo Artículo 24 por la Educación Inclusiva, el INADI, la Red por los Derechos de las Personas con Discapacidad, la Asociación por los Derechos Civiles y expertos en materia de educación y discapacidad, Alan inició un amparo para que se reconociera su derecho fundamental a la educación, sin discriminación y sobre la base de la igualdad de oportunidades, y se le entregue su título secundario oficial. La Justicia ratificó el derecho a la educación inclusiva, en el día mundial del síndrome de Down. (ACIJ, 2017). Disponible en: http://acij.org.ar/la-justicia-ratifico-el-derecho-laeducacion-inclusiva-en-el-dia-mundial-del-sindrome-de-down/.

10 Noelia Garella tiene síndrome de Down, lo que no le fue obstáculo para estudiar y egresar con el título de maestra jardinera del Instituto terciario Dr. Antonio Sobral en 2007. Cursó la escuela como alumna integrada en el Colegio Santa Infancia de las Hermanas Concepcionistas, y el terciario en el Sobral. (Mariana Otero, 2012) Disponible en: http://www.lavoz.com. ar/ciudadanos/maestra-especial-que-conquisto-villa-cornu 
amen de la importancia del planteamiento en la sociedad de este tema, solo ha generado presión en esos casos individuales, pero en el resto de los niños la situación sigue igual y las instituciones como el mismo sistema educativo sigue reticente a cumplir con los derechos adquiridos y avances normativos.

En esos momentos bastaba con sintonizar cualquier medio para escuchar hablar de la presente temática, muchos medios con el objetivo de concientizar y generar presión para lograr su efectiva puesta en práctica, pero otros tantos dando información errónea, como usualmente decimos, "desinformando".

La comunicación es una herramienta persuasiva de una gran importancia para nuestra sociedad, ya que influye sobre la manera de actuar o de pensar de las personas, como también logra modificar la forma en que los hombres conocen y comprenden la realidad que los rodea. Es un instrumento político para lograr o no un cambio de paradigma o forma de ver el mundo.

A su vez, resulta ser fundamental para lograr una verdadera transformación, remodelar el lenguaje, derribar mitos, sensibilizar a la comunidad, romper con los estereotipos, visibilizar las barreras, y es un eje fundamental para acompañar los avances normativos.

Si analizamos cualquier noticia cuyo el eje está puesto en los niños y adolescentes con discapacidad y el sistema educativo, es notable que entienden a la educación inclusiva como la educación donde se permite el ingreso a la persona con discapacidad a la escuela común, sin dejar atrás la escuela "la especial". Pero como mencionamos anteriormente, la educación inclusiva no es eso, sino una "educación para todos", visibilizando la diversidad como la mayor riqueza humana existente.

Se trata de proveer una oferta que atienda a la diversidad, y que sea adecuada a las particularidades de los sujetos, sin que ello redunde en la fragmentación del sistema educativo. Esto supone la búsqueda constante de los caminos adecuados para lograr este objetivo. 
Asimismo, la diversidad es una característica intrínseca de los sujetos (y en este caso de los alumnos), por lo tanto, no debe ser vista como un problema u obstáculo que hay que enfrentar, sino como una experiencia enriquecedora. No alcanza con incluir a los niños y jóvenes dentro de la escuela. Toda acción de inclusión educativa, debería tener como fin primordial el logro de aprendizajes significativos y de calidad en los estudiantes. Esto supone no sólo la adquisición de contenidos "sustantivos" sino la capacidad de resolver problemas y aprender a lo largo de toda la vida. (UNESCO, 2007)

La comunicación es un proceso de plática pública, y es importante que ésta tenga como base el paradigma social y de derechos de la discapacidad, buscar eliminar las barreras que la sociedad impone a los grupos históricamente vulnerados y construir conciencia social. Reflexionar y promover prácticas no discriminatorias, la libertad personal y una verdadera transformación social que garantice la verdadera educación inclusiva. La vida de las personas con discapacidad es ahora. El tiempo del cambio cultural es hoy. (COPIDIS y otro, 2017)

\section{IV. ¿Qué impacto genera en el proyecto de vida de las personas con discapacidad la forma en que se les ha otorgado el título secundario? Relevamiento en la Ciudad de La Plata sobre las barreras que impiden a los/as niños/as con discapacidad para obtener su título en igualdad de condiciones que el resto de sus compañeros/as}

En las entrevistas realizadas en la Ciudad de La Plata a alumnos con discapacidad que cursan su época escolar, como también graduados, personal docente, equipo directivo, equipo de orientación escolar, Directores/as, Inspectores/as, familias y personas que se acercan sobre éste tema a Clínicas Jurídicas de Derechos Humanos, Comisión Discapacidad ${ }^{11}$ de la Facultad

\footnotetext{
11 Clínicas Jurídicas es un programa del Área de Extensión universitaria de la Facultad de Cs. Jurídicas y Sociales, de la Universidad Nacional de La Plata, dirigida por el Abog. José Maria Martocci, que apunta a prestar Servicios Jurídicos a distintas problemáticas
} 
de Ciencias Jurídicas y Sociales - Universidad Nacional de La Plata (en adelante UNLP) se ha indagado sobre su punto de vista acerca de qué situaciones, características, condiciones y/o obstáculos, existían a la hora de obtener su título y proseguir su camino hacia un empleo o institución educativa terciaria o universitaria. Como también prácticas educativas tendientes a lograr la Educación Inclusiva de las Personas con discapacidad.

Dichas respuestas en base a sus experiencias de la vida cotidiana tienen en común frustraciones, angustias, preguntas, y promesas. Frustraciones, por ejemplo, en el caso de una graduada que quiso proseguir con sus estudios y comenzar este año la carrera de "Maestra Inicial" en la ciudad de La Plata, obteniendo como respuesta la negativa de diversos Institutos de Formación Docente a raíz de su título de secundaria, ya que el mismo no tenía validez, con lo cual no podía ser inscripta y proseguir sus estudios. De igual modo, las respuestas fueron, en conclusión, que por cuestiones formales no podía acceder a este sueño de ser en un futuro una Maestra de educación Inicial.

Su madre relataba que su bronca no es que en un futuro su hija no quiera terminar la carrera, o no pueda lograrlo por diversos

colectivas vinculadas a la Discapacidad, que permitan modificar las prácticas que obstaculizan la protección de derechos fundamentales, protegidos por la Convención sobre los Derechos de las Personas con Discapacidad, con Jerarquía Constitucional.

Aspira a potenciar el respeto por la dignidad humana, la igualdad y la libertad personal, propiciando la inclusión social, y sentándose sobre la base de determinados principios: autonomía y vida independiente, no discriminación, accesibilidad universal, educación inclusiva, diálogo civil, entre otros.

Es un lugar donde se aborda la cuestión de la Discapacidad, enfocada a la Accesibilidad, tendencia a adaptar el entorno y los espacios públicos a las necesidades de las personas con discapacidad, a fin de evitar la exclusión social, la implementación de mecanismos de apoyo, salvaguardas y ajustes razonable, tendientes a que las personas con discapacidad puedan ejercer su capacidad jurídica -y por ende sus derechos- en iguales condiciones que los demás.

Además, busca estimular en los estudiantes y jóvenes graduados, el desarrollo de diversas capacidades, destrezas y valores a partir de una actitud auto-reflexiva y crítica respecto de los casos de interés público vinculados a la Discapacidad que se presenten, permitiéndoles sumarse a un equipo de trabajo que, a la vez que aprende, actúa como verdadero agente de cambio social. 
motivos de la vida, su bronca es que pese a haber cursado toda su trayectoria escolar como los niños y adolescentes lo hacen, a ella se le entregó un título que no le reconoce su trayectoria, su esfuerzo escolar, un simple papel que cuando ella lo presenta le dicen que "no es válido", ya que "no es homologable".

Para el sistema educativo es diferente del resto, no se encuentra en los parámetros de "normalidad" que exigen para que una persona pueda acceder a estudios superiores, por ser un Persona con Discapacidad y por tener Síndrome de Down tienen el prejuicio que usualmente se dice "no va a poder". Razón por la cual no le dan siquiera la posibilidad de que ella pruebe si es realmente su carrera, si es la profesión que el día de mañana quiere ejercer, si va a poder llevar al día su estudio, si le va a gustar o no. El mismo sistema de antemano, y anticipándose al futuro, le contesta todos estos interrogantes y le responde un NO.

Pensemos un poco, ¿éste es el paradigma médico o el paradigma social? ¿Avanzó mucho más la normativa internacional que como sociedad? ¿Culturalmente en qué sistema estamos? Al parecer seguimos haciendo foco en la discapacidad, como si ello está por encima del ser persona. Se antepone y la sociedad construye barreras (in)visibles que día a día les ponen obstáculos que no se los pone su "síndrome" sino que es la propia sociedad la que se los colocan y no le permiten acceder a los derechos fundamentales como lo es la educación.

En cuanto a los relatos que generaban angustias, uno de tantos es el caso de un joven graduado, cuyo paso por la escuela fue una experiencia significativa y enriquecedora para su formación durante la cual menciona haberse sentido verdaderamente incluido y querido. Lo cual se logró gracias al trabajo mancomunado entre dicha escuela, su familia, la maestra integradora, los profesionales privados y personal de la escuela especial. A la escuela común de gestión privada, concurrió de la misma forma que todos sus compañeros, con la misma carga horaria, cursando todas las materias, rindiendo exámenes 
finales y sin necesidad de concurrir a la escuela especial, pero a pesar de lo expuesto, al terminar el secundario su título no fue homologable.

Promesas para el caso de Docentes tanto de las escuelas Comunes como de las Especiales, que se sienten desprotegidas, que quieren luchar por lograr una verdadera inclusión educativa, pero cuando tratan de trabajar en conjunto ambas escuelas, surgen resistencias a veces de la institución de la escuela común, como otras tantas de la escuela especial. Éstas resistencias e incomunicaciones, son a raíz de personas que mantienen concepciones en el anterior paradigma como también por lucha de poderes por quien acredita (si acredita común las materias o especial), generando resultados frustrantes a la hora de que la institución de la escuela común sea la encargada de la educación. Aunque el alumno/a no tenga la necesidad de concurrir a la escuela especial, se sigue sosteniendo que por ser una Persona con Discapacidad debe necesariamente pasar por ella, o ir algunos días de la semana a ésta.

Preguntas sobre el porqué la Provincia de Buenos Aires, pese a tener la Convención, resoluciones, Legislación y Jurisprudencia, se niega a cumplir con el Derecho Humano a la Educación Inclusiva de todos los jóvenes que se gradúan y quieren su título en igualdad de condiciones que el resto. ¿Son motivos políticos?, ¿Pensamientos retrógrados?, ¿cuestiones de poder?, no se sabe con exactitud cuáles son los motivos por los cuales no se cumple con la normativa, pero eso no tiene injerencia para nosotros ya que la obligación del sistema educativo está en cumplir con los derechos humanos, sin distinción y nuestra obligación es luchar porque esto ocurra.

Retomando es importante resaltar que la certificación igualitaria -además de ser condición necesaria para la participación plena de las personas con discapacidad en la vida comunitariaconstituye una dimensión fundamental del derecho a la educación inclusiva, pues no se puede hablar de un sistema educativo inclusivo cuando las escuelas o el Estado permiten que las personas con discapacidad asistan a escuelas comunes pero 
paralelamente se niegan a reconocer o validar los conocimientos que adquieren en ellas. El acceso a la educación superior y el aprendizaje durante toda la vida solo son posibles si el Estado otorga instrumentos que sirvan para acreditar los saberes que las personas con discapacidad han adquirido durante su educación primaria y secundaria. (COPIDIS y otro, 2017)

El Comité de Naciones Unidas sobre Derechos de las Personas con Discapacidad señaló que en el Estado Argentino la implementación del principio de educación inclusiva "se ve limitada, en la práctica, por la falta de adecuación de los programas y planes de estudio a las características de los educandos con discapacidad, así como por la prevalencia de barreras de todo tipo que impiden que las personas con discapacidad accedan al sistema educativo en condiciones de igualdad y no discriminación al resto de los estudiantes". A su vez, "el Comité observa con preocupación que en la armonización de la Convención con el ordenamiento jurídico nacional persisten importantes inconsistencias con los principios y mandatos de este tratado; especialmente, en lo relativo al igual reconocimiento de la persona con discapacidad ante la ley. Igualmente observa con preocupación que el hecho de que no toda la legislación provincial del Estado parte esté armonizada con la Convención, genera disparidades en la forma en la que a nivel local se entienden los derechos de las personas con discapacidad y a su efectiva implementación". (Comité sobre los Derechos de las Personas con Discapacidad. Naciones Unidas, 2012)

Con lo cual, amén de transformar la legislación y normativa del Sistema educativo, el Estado Argentino debe velar por su aplicación y que la Educación primaria, secundaria, terciaria y universitaria pueda ser para todos y no para algunos estudiantes.

En el relevamiento realizado la mayoría de los alumnos entrevistados tienen problemas con su Derecho a la Educación Inclusiva, accesibilidad, titulación, permanencia e ingreso, como también, sufren de segregación y la integración vestida de inclusión. Los pocos niños que tuvieron la "suerte", porque así es como está la situación del sistema escolar actual, de contar con 
una verdadera educación inclusiva, fue gracias a la lucha de sus familias, organizaciones y asociaciones en lucha constante por hacer valer sus derechos, y varias escuelas que toman conciencia y cumplen con la obligación de velar por el derecho a la Educación inclusiva consagrado tanto convencional como constitucionalmente.

Sabemos que esto no debe ser así, los padres nos han contado que ellos tienen que buscar "la escuela que es inclusiva", incluso muchas veces en vez de ir a la escuela que tienen a unas pocas cuadras, tienen que hacer un trayecto mucho más largo para que su hijo pueda ir a una escuela que cumpla con la obligación de respetar y velar por su derecho universal a la educación. El sistema escolar debe ser inclusivo, no en unas tantas escuelas, sino el sistema en general.

Recordemos la importancia de la escuela, ya que es la primera y fundamental instancia de socialización, crecimiento, aprendizaje y desarrollo integral de la persona, con lo cual debemos centrarnos en que estamos en otro paradigma de la discapacidad, un paradigma social y de derechos, y es obligación del Estado Argentino velar por ello. El objetivo principal del Sistema Educativo debe ser que todos los chicos puedan acceder a todos los niveles de la educación, y a su vez que sea una educación Inclusiva, sin discriminación y de calidad.

\section{Reflexiones finales}

A través del desarrollo del presente trabajo, tomamos consciencia de que pese a los avances en la normativa interna, que debería ajustarse a la Convención de las personas con Discapacidad, hay una puja de tensiones y motivos de poder, entre otros factores posiblemente políticos que obstaculizan el cumplimiento efectivo en Argentina de una educación inclusiva de calidad y el título secundario para las Personas con Discapacidad en igualdad de condiciones y sin discriminación.

A sabiendas de las dificultades existentes, decidimos emprender una lucha para superar las desigualdades, ya que, la 
discriminación de cualquier tipo no tiene por qué estar presente en nuestra vida diaria y aún resta mucho por lograr.

Las personas con discapacidad, como todo ser humano, deben tener y gozar de los derechos fundamentales, sin barreras de ningún tipo, desde las claramente visibles como el que no haya una rampa, a las barreras (in)visibles como el acceso a la educación y el trabajo. Somos seres humanos y ante todo personas. Vivimos en un mundo donde históricamente nos hemos hecho daño a nosotros mismos, creímos en un ideal de "normalidad", le temíamos a la diferencia, buscábamos una igualdad inexistente, pero aprendimos a valorar la diferencia, nos dimos cuenta y debemos modificar las prácticas cotidianas que vulneran derechos y potencian la segregación.

Debemos comprometernos, mirar a nuestro alrededor y no ser indiferentes, potenciar el respeto de la dignidad humana y colaborar en la transformación social como partes de la misma.

Toda persona con discapacidad que haya cumplido con su trayectoria escolar, debe tener su título en igualdad de condiciones que el resto. Debemos garantizar que pueda acceder a estudios no solo primarios y secundarios sino también terciarios y universitarios. Gozar del derecho al trabajo, autonomía y participación social.

Para esto debemos colaborar en el presente para lograr lo que queremos como futuro, una construcción colectiva basada en la reflexión y problematización para derribar los muros del acceso efectivo a la justicia de las personas en condición de vulnerabilidad. Batallar contra las diferentes formas de discriminación y opresión, proponiendo la modificación de las estructuras sociales.

Tengamos presentes el lema "Nada sobre nosotros sin nosotros”, expresión utilizada para comunicar la idea de que no puede decidirse una política pública sin contar con la participación completa y directa de los miembros del grupo afectado por dicha política, en este caso las Personas con Discapacidad. Éstas tienen derecho a la participación y a la consulta previa, por lo 
tanto es importante alzar la voz para que sean escuchados, hacer valer sus derechos y que se cumpla efectivamente la Convención Internacional de las Personas con Discapacidad.

No debemos defraudar nuestras esperanzas, tomemos como desafío el luchar por un sistema educativo que acepte, valore la diversidad y se engrandezca con ella. Por una Educación para todos.

\section{Bibliografía}

Blanco Guijarro, R. (2008) La educación inclusiva: el camino hacia el futuro, UNESCO.

Camilloni, A. R. W. (s.f.) Justificación de la Didáctica ¿Por qué y para qué la didáctica? (s.l.) (s.n.).

Cobeñas, P. (2014). Buenas prácticas inclusivas en la educación de personas con discapacidad en la provincia de Buenos Aires y desafios pendientes. Buenos Aires: Asociación por los Derechos Civiles.

Conferencia Internacional De Educación (48: 2008 noviembre 25-28, Ginebra Suiza) "La Educación Inclusiva: El Camino Hacia El Futuro". Ginebra: Organización De Las Naciones Unidas Para La Educación, La Ciencia y La Cultura, UNESCO, 2008.

COPIDIS (Comisión para la Plena Participación e Inclusión de las Personas con Discapacidad) y Grupo Art. 24 por la Educación Inclusiva, (2017) Manual de Educación Inclusiva, Educación Inclusiva y de calidad, un derecho de todos

Freire, Paulo. (1994). Cartas a quien pretende enseñar. (s.1.): Siglo XXI.

Freire, Paulo. (2004). El grito Manso, $1^{\circ}$ Ed., México: Siglo XXI.

Freire, Paulo. (2006). Pedagogía de la autonomía: saberes necesarios para la práctica educativa. (s.1.): Siglo XXI.

Grupo Art. 24 por la Educación Inclusiva (2016). Educación Inclusiva. Bases para la incidencia en políticas públicas. (s.1.): Grupo Art. 24.

Infojus (2012). Discapacidad, Justicia y Estado $N^{o}$ 1. (s.1.): Ministerio de Justicia y Derechos Humanos de la Nación. ADAJUS.

Palacios, A. (2008). El modelo social de discapacidad: orígenes, caracterización y plasmación en la Convención Internacional sobre los Derechos de las Personas con Discapacidad. (s.1.): CERMI. 
Tenti Fanfani, E. (1993) La escuela vacía, deberes del Estado y responsabilidades de la Sociedad. Buenos Aires, Losada.

Torres, Rosa María (1985): Sobre Educación Popular: Entrevista a Paulo Freire, México: CREFAL.

\section{Documentos de Organismos Internacionales}

Comité sobre los Derechos de las Personas con Discapacidad (2016). Observación General No. 4 sobre el Derecho a la Educación Inclusiva, CRPD/C/GC/4.

Comité sobre los Derechos de las Personas con Discapacidad. Naciones Unidas. Observaciones finales sobre el informe inicial de Argentina, aprobadas por el Comité en su octavo período de sesiones (17 a 28 de septiembre de 2012).

Convención por los Derechos de las Personas con Discapacidad y su Protocolo Facultativo aprobados el 13 de diciembre de 2006. Naciones Unidas. En Argentina, Ley Nacional No 26.378, 2008.

Declaración de Salamanca (1994). Aprobada por aclamación en la ciudad de Salamanca, España, el día 10 de junio de 1994. Unesco.

Informe de la Oficina del Alto Comisionado de las Naciones Unidas para los Derechos Humanos (2013) Estudio temático sobre el derecho de las personas con discapacidad a la educación, A/ $\mathrm{HRC} / 25 / 29$.

Taller Regional Preparatorio sobre Educación Inclusiva América Latina, Regiones Andina y Cono Sur Buenos Aires, Argentina. La Inclusión Educativa en la Argentina de hoy. Definiciones, logros y desafíos a futuro. 2007. UNESCO International Bureau of Education.

UNESCO (2008) La educación inclusiva: el camino hacia el futuro.

\section{Leyes y Resoluciones}

Resolución 311/16 Consejo Federal de Educación

Resolución 84/09 del Consejo Federal de Educación

Resolución 2945/17 del Ministerio de Educación de la Nación

Resolución 4635/11 de la Dirección General de Cultura y Educación 